\title{
Repetitive proteins from the flagellar cytoskeleton of African trypanosomes are diagnostically useful antigens
}

\author{
M. IMBODEN ${ }^{1}$, N. MÜLLER ${ }^{2}$, A. HEMPHILL ${ }^{2}$, R. MATTIOLI ${ }^{3}$ and T. SEEBECK ${ }^{1}$ \\ ${ }^{1}$ Institute of General Microbiology, University of Bern, Baltzerstrasse 4, 3012 Bern, Switzerland \\ ${ }^{2}$ Institut für Parasitologie, Universität Bern, Länggasstrasse 122, 3012 Bern, Switzerland \\ ${ }^{3}$ International Trypanotolerance Centre (ITC), PMB 14, Banjul, The Gambia
}

(Received 25 July 1994; revised 8 September 1994; accepted 15 September 1994)

\begin{abstract}
SUMMARY
Trypanosome infection of mammalian hosts leads, within days, to a strong early response against a small, distinct number of parasite proteins. One of these proteins is the variable surface glycoprotein (VSG). Most of the others are apparently non-variable, intracellular trypanosome proteins. Two of these antigens $I_{2}$ and $I_{17}$ are now characterized at the molecular level. Both exhibit a highly repetitive amino acid sequence organization, but they show no sequence similarity either to each other or to any other proteins known to date. Preliminary serological analyses indicate that both allow the early, sensitive and specific detection of infections with different species of trypanosomatids, making them interesting candidates for the development of diagnostic tools for trypanosomiasis detection.
\end{abstract}

Key words: Trypanosoma brucei brucei, Trypanosoma congolense, Trypanosoma vivax, cytoskeleton, repetitive protein, antigen, diagnosis.

\section{INTRODUCTION}

The strong immune response of a mammalian host infected with African trypanosomes is mainly directed against the variant surface glycoprotein, VSG (Cross, 1990) and is not protective (Seed \& Sechelski, 1987; DeGee, Levine \& Mansfield, 1988). This lack of protectivity is because of the high variability of the parasite's surface coat during the course of the infection. Much effort has been directed towards the search for invariant antigens both as tools for diagnosis and as potential targets for vaccine development. Such antigens are often high molecular weight proteins and associated with the flagellum or the cytoskeleton of the parasite (Lafaille et al. 1989; Ruiz et al. 1990; dos Santos et al. 1992). Müller et al. (1992) have identified 2 invariant, repetitive high molecular weight proteins associated with the cytoskeleton of the parasite which exhibited a high immunodiagnostic sensitivity. Time-course studies of the infection demonstrated that these 2 antigens were representatives of a whole group of high molecular weight (HMW) antigens which are all recognized very early in infection (Müller et al. 1993). Based on these findings, we have designed a screening strategy specifically aimed at identifying additional members of this group. A cDNA library from bloodstream $T$. gambiense was screened with affinity-purified antibodies against high molecular weight cytoskeleton proteins. The present study reports the identification of two new antigens, $I_{2}$ and $I_{17}$, by this strategy. Both exhibit a high repetitive sequence organization, and both are structural elements of the cytoskeleton.

\section{MATERIALS AND METHODS}

\section{Trypanosomes}

The trypanosomes used for cytoskeletal preparations, Western blot analysis, immunofluorescense and immunogold electron microscopy were all procyclic forms of Trypanosoma brucei brucei clone EATRO 427. They were grown in SDM-79 medium (Brun \& Schönenberger, 1979) supplemented with haemin and $5 \%$ foetal calf serum. The cells were harvested during exponential growth at a cell density of about $5 \times 10^{6} / \mathrm{ml}$.

\section{Sera}

Trypanosome cytoskeletons were prepared as described by Hemphill et al. (1991). Briefly, trypanosomes from $10 \mathrm{ml}$ of culture were washed 3 times in MME (10 mm Mops/1 mM $\mathrm{MgCl}_{2} / 0.2 \mathrm{~mm}$ EGTA, $\mathrm{pH} 6.9$ ) and incubated in MME containing $0.5 \%$ Triton X-100 for $10 \mathrm{~min}$ on ice. After a centrifugation at $3000 \mathrm{~g}$ for $10 \mathrm{~min}$ the Triton $\mathrm{X}-100$-insoluble cytoskeleton fraction was washed once in PBS (137 mM NaCl/2.7 mM KCl/8.1 mM $\mathrm{Na}_{2} \mathrm{HPO}_{4} /$ $1.5 \mathrm{mM} \mathrm{KH}_{2} \mathrm{PO}_{4}, \mathrm{pH} \mathrm{7.2)}$ and resuspended in $100 \mathrm{ml}$ of PBS. Rats were inoculated intraperitoneally with this cytoskeleton material either in complete (1st inoculation) or incomplete ( 2 nd and 3 rd inoculation) Freund's adjuvants. Blood was finally collected by cardiac puncture. Sera from experimentally infected mice were taken 14 days after an experimental infection with the Lou'Tat 1 strain of $T$. b. brucei (DeGee et al. 1988). The bovine sera used for the evaluation 
of the diagnostic sensitivity originated from cyclical or experimental infections of N'Dama and Zebu cattle with either $T . b$. brucei, $T$. vivax or $T$. congolense. The control sera originated from young (10 months) Zebu cattle. All bovine sera were kindly provided by Dr R. Mattioli, International Trypanotolerance Centre (ITC) in Banjul, The Gambia.

\section{Lambda gt11 cDNA expression of T. b. gambiense}

The cDNA expression library from bloodstream form $T . \quad b$. gambiense (stock TREU 1285) was constructed in the cloning vector $\lambda \mathrm{gt} 11$ as described (Barnes et al. 1989) and was kindly provided by $\mathrm{Dr}$ M. Selkirk (Department of Biochemistry, Imperial College of Science, Technology and Medicine, London).

\section{Immunoscreening of a $c D N A$ library and construction of recombinant $\lambda$ lysogen}

The $\lambda$ gt11 expression library of $T . b$. gambiense was screened for clones corresponding to high molecular weight proteins. The antibody used for screening was prepared as follows. Whole procyclic trypanosome lysates (see below) were fractionated by SDS-PAGE and blotted onto nitrocellulose filters. After staining with $0.04 \%$ Ponceau $\mathrm{S}$ in $10 \%$ acetic acid, the high molecular weight region of the filter ( $>180 \mathrm{kDa}$ ) was excised and used for affinitypurification of the antibodies from hyperimmune rat serum raised against trypanosome cytoskeletons (Müller et al. 1992).

\section{Affinity purification of antibodies on fusion protein}

Affinity purification of antibodies from rat anticytoskeleton hyperimmune serum on $\beta$-galactosidase fusion proteins was done as described by Müller $e t a l$. (1992). The affinity-purified antibodies were used at a dilution of 1:10 for Western blot analysis, immunofluorescence and immunogold electron microscopy.

\section{Subcloning of $\lambda g t 11$ inserts}

The cloning of recombinant $\lambda \mathrm{I}_{2}$ and $\lambda \mathrm{I}_{17}$ cDNA inserts into Bluescript plasmid KS-plus (Stratagene) was performed as described by Rindisbacher et al. (1992).

\section{Western blot analysis}

The trypanosomal fractions used for the Western blot analysis were prepared as follows. For whole cell lysates $4.5 \times 10^{8}$ trypanosomes were washed once in MME and then lysed in $1 \mathrm{ml}$ of sample buffer
(Laemmli, 1970). The cytoskeletal fraction was obtained by resuspending $4.5 \times 10^{8}$ cells in $\mathrm{MME}$ containing $0.5 \%$ Triton X-100 and incubating them for $10 \mathrm{~min}$ on ice (Hemphill et al. 1991). For the preparation of the flagellar fraction, cytoskeletons were resuspended in $2 \mathrm{ml}$ of $0.1 \times \mathrm{MME}$ containing $1 \mathrm{M} \mathrm{NaCl}$ (Schneider, Hemphill \& Seebeck, 1988). After sonication for $15 \mathrm{~s}$ the suspension was kept on ice for $20 \mathrm{~min}$. The cytoskeletons and the flagellar suspension as well as the supernatant of the cytoskeletons were all precipitated with 4:1 methanol/ chloroform (Wessel \& Flügge, 1984) to remove salts and detergent and the final protein pellets were solubilized in $1 \mathrm{ml}$ of sample buffer. The Western blot analysis for the determination of the diagnostic sensitivity of $I_{2}$ and $I_{1 z} / \beta$-galactosidase fusion proteins was performed as described by Müller $e t$ al. (1992). Serum antibodies to $\beta$-galactosidase and other components of $E$. coli were previously removed by pre-adsorption of the bovine sera to a lysate of $\lambda$ gt11 lysogens from strain Y 1089 (Huynh, Young \& Davis, 1985). The peroxidase-dependent colour reaction was performed using either $3,3^{\prime}$-diaminobenzidine tetrahydrochloride as described by Vogel et al. (1988) or Enhanced Chemoluminescence (ECL, Amersham) according to the manufacturer's specifications.

\section{$D N A$ sequencing and hybridization}

Nested deletions of DNA fragments were prepared with exonuclease III double-stranded nested deletion kit (Pharmacia, Sweden); subclones were double-strand sequenced using the Sequenase DNA sequencing kit (United States Biochemical Corporation). For hybridization analysis, DNA was blotted onto nylon filters and was hybridized in $0.1 \times \mathrm{SSC}\left(15 \mathrm{~mm} \mathrm{NaCl}, 1.5 \mathrm{mM} \mathrm{Na}_{3}\right.$ citrate), $4 \times$ Denharts, $0.08 \%$ SDS, $80 \mathrm{~mm}$ sodium phosphate $\mathrm{pH} 6.5,80 \mathrm{mg} / \mathrm{ml}$ herring sperm DNA at $65^{\circ} \mathrm{C}$ for $14 \mathrm{~h}$. The filters were washed 3 times for $10 \mathrm{~min}$ in $0.1 \times \mathrm{SSC}, 0.1 \% \mathrm{SDS}$ for $20 \mathrm{~min}$ at $65^{\circ} \mathrm{C}$. Both hybridizations were done using purified inserts of $\lambda I_{2}$ and $\lambda I_{17}$ respectively.

\section{Immunofluorescence}

Trypanosomes were cultivated as described above. After 3 washes in PBS, cells (approximately $10^{7} / \mathrm{ml}$ ) were applied to cover-slips previously coated with $100 \mu \mathrm{g} / \mathrm{ml}$ polylysine and were allowed to settle for $1 \mathrm{~h}$ in a moist chamber at room temperature. Coverslips were then rinsed twice in MME and treated with $2 \%$ formaldehyde in MME for $15 \mathrm{~min}$. The fixed trypanosomes were permeabilized in methanol at $-20^{\circ} \mathrm{C}$ for $10 \mathrm{~min}$ and subsequently rehydrated in PBS for $30 \mathrm{~min}$. For the preparation of cytoskeletons, cells were extracted on the cover-slips with MME containing $0.5 \%$ Triton X-100 for 5 min 
at room temperature prior to fixation. After rehydration, cover-slips were incubated for $1 \mathrm{~h}$ in blocking buffer (PBS containing $100 \mathrm{~mm}$ L-lysine and $1 \% \mathrm{BSA}$ ). For immunostaining, cover-slips were incubated for $45 \mathrm{~min}$ in a moist chamber at room temperature with affinity-purified antibody diluted $1: 10$ in blocking solution. After washing the coverslips 6 times in PBS, FITC-conjugated rabbit antirat Ig (Dakopatts, Denmark; diluted $1: 100$ in blocking solution) was applied as described for the affinity-purified antibodies. After removing excess second antibody by washing 6 times in PBS, coverslips were mounted on a slide using a mixture of gelvatol/glycerol in PBS as embedding medium (Lawson, 1983).

\section{Immunogold electron microscopy}

Washed trypanosomes were allowed to settle onto a Formvar carbon-coated grid for $1 \mathrm{~h}$ prior to extraction in MME containing $0.5 \%$ Triton X-100 as described above. After rinsing the cover-slips in MME, the cytoskeletons were fixed in $3.7 \%$ paraformaldehyde in MME, incubated in blocking buffer and exposed to the antibodies as described for immunofluorescence, with the modification that the second antibody was an affinity-purified goat anti-rat IgG coupled to $10 \mathrm{~nm}$ colloidal gold (Janssen, Beerse, Belgium), diluted $1: 5$ in $20 \mathrm{~mm}$ Tris $-\mathrm{HCl}$, $\mathrm{pH} 82$, containing $1 \% \mathrm{BSA}$. After washing the grids 6 times for $5 \mathrm{~min}$ in PBS, they were fixed with $2 \%$ glutaraldehyde in PBS for 20 min. Grids were then washed 6 times in $\mathrm{H}_{2} \mathrm{O}$, and negative staining was carried out in 3 changes of $1 \%$ uranyl acetate, $20 \mathrm{~s}$ each. Finally, grids were air-dried and electron micrographs were taken with a Philips EM 300 microscope operating at $60 \mathrm{kV}$.

\section{RESULTS}

High molecular weight proteins associated with the cytoskeleton are antigens

When whole trypanosome extracts were anlaysed by immunostaining with infected bovine serum, a discrete banding pattern was observed (Fig. 1A). Several distinct bands could be discerned in the 30-100 $\mathrm{kDa}$ region, and heavy staining was observed in the high molecular weight range, in agreement with earlier observations (Müller et al. 1992). Unexpectedly, the staining patterns obtained with whole cell lysates (Lane 1) and with purified cytoskeletons (Lane 2) were very similar, indicating that antibodies in the infected serum are mainly directed against cytoskeletal components. This notion is further supported by the observation that a qualitatively similar staining pattern was also obtained with hyperimmune rat serum raised against trypanosomal cytoskeletons (Fig. $1 \mathrm{~B}$ ).

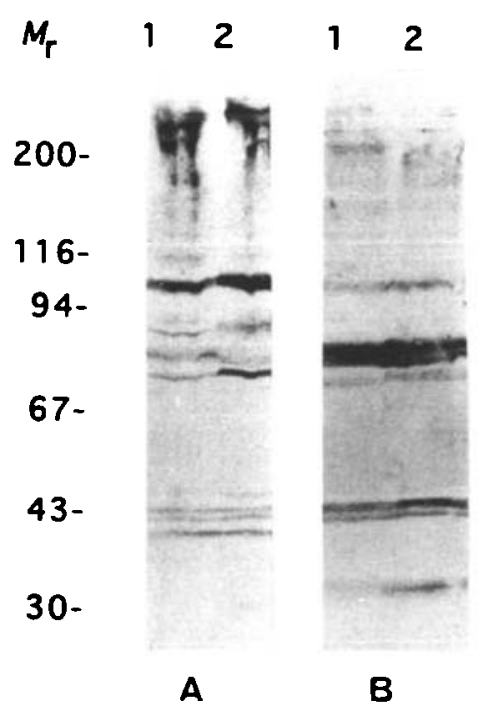

Fig. 1. Western blot analysis of whole trypanosomal cell extracts (Lane 1) and cytoskeletons (Lane 2) probed with $(A)$ a bovine serum taken 14 days after infection and (B) with an anti-cytoskeleton rat hyperimmune serum. Molecular weight markers are given in $\mathrm{kDa}$.

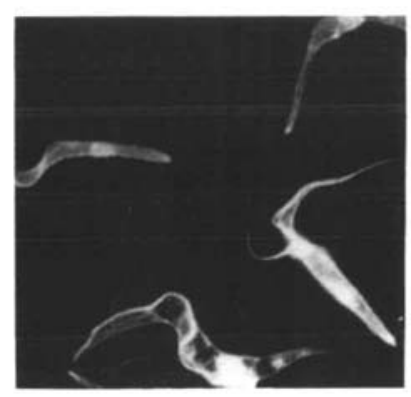

$\mathbf{A}$

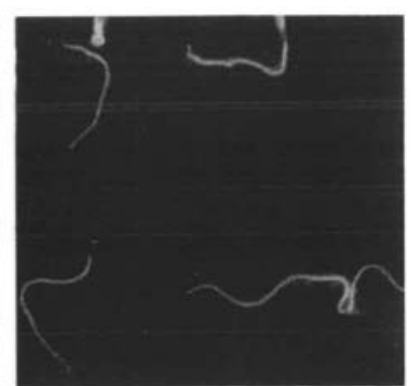

B
Fig. 2. Immunofluorescent staining of fixed trypanosomal cytoskeletons probed with (A) anticytoskeleton rat hyperimmune serum and (B) affinity-purified anti-HMW antibody.

In order to select antibodies with specificity against high molecular weight (HMW) proteins, the $>180 \mathrm{kDa}$ region of gel-fractionated whole trypanosome extracts was used for affinity purification of antibody from hyperimmune anti-cytoskeleton serum. Immunofluorescence microscopy shows that hyperimmune serum against cytoskeletons reacts with almost the entire cell (Fig. 2 A) whereas affinitypurified $\mathrm{HMW}$-specific antibodies predominantly stain the flagellum (Fig. 2 B).

Results presented in Figs 1 and 2 indicate that most of the host antibodies formed in the first 2 weeks of infection react with components of the cytoskeleton. Furthermore, many of the antibodies which are specific for HMW proteins react with components of the flagellum, suggesting that the flagellum is a source of strongly immunogenic antigens of high molecular weight. 
1 PHBVGAHGQ TQIAVGYAPB PSBLBABABI VVLBLGPYAB

4 RPVCBAVNID GBGBKMDNLE GVLIYAGSHP BSRCIPIBIV

90 BDLTKABELDBPVADTEVABKBPTDEBVIPBKBIPDTBAABEQPA (1)

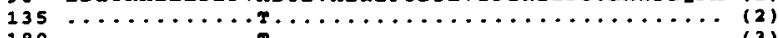

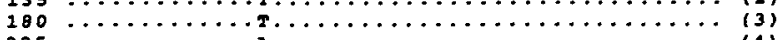

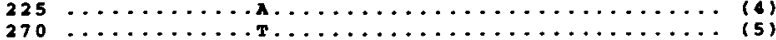

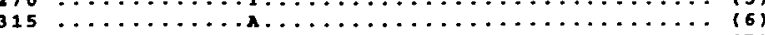

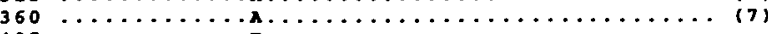

$05 \quad \ldots \ldots \ldots \ldots$.

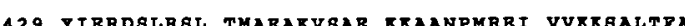

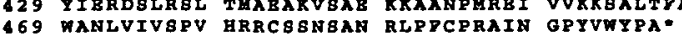

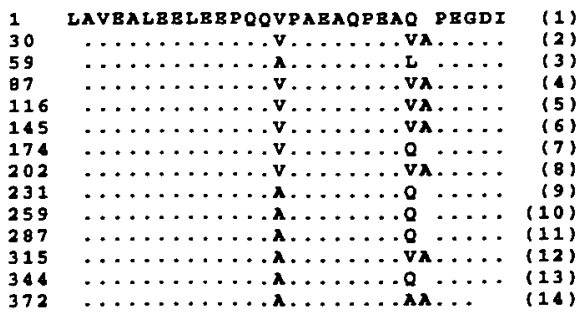

399 GBALVELDVB BFD.

Fig. 3. Sequence analysis of the inserts in $\lambda I_{2}$ and $\lambda I_{17}$. (A) Deduced amino acid sequence from the $\lambda \mathrm{I}_{2}$ cDNA sequence. Between amino acids 90 and 428 the sequence consists of seven and a half highly conserved repeat units of 45 amino acids. One amino acid can be either alanine or threonine. (B) Amino acid sequence deduced from the $\lambda \mathrm{I}_{17}$ cDNA sequence. The sequence consists of 14 highly conserved repeat units of either 29 or 28 amino acids. The first amino acid (leucine) of the given sequence does not belong to the repeat. At 2 positions within the repeat amino acid exchanges occur: from valine to alanine, and from glutamine to leucine or to valine plus alanine or to alanine plus alanine. The $\mathrm{C}$ terminus of $I_{17}$ consists of 13 unrepeated amino acids. In both panels, identical amino acids are indicated with a period and in-frame stops are marked by asterisks. The sequences have been deposited in the GenBank/EMBL data library under the accession numbers $Z 36280\left(\mathrm{I}_{2}\right)$ and $\mathrm{Z36281}\left(\mathrm{I}_{17}\right)$.

\section{Screening of a T. b. gambiense expression library with an affinity-purified antibody}

In order to identify genes for such HMW flagellar antigens, a $\lambda \mathrm{gt11}$ library of bloodstream $T . b$. gambiense (Barnes et al. 1989) was screened with the anti-HMW protein antibody. The phages recovered from this screening represented a number of different genes, two of them, $I_{2}$ and $I_{17}$, were further analysed in this study.

\section{$I_{2}$ and $I_{17}$ both show repetitive sequence motifs}

The inserts of recombinant $\lambda \mathrm{I}_{2}$ and $\lambda \mathrm{I}_{17}$ were subcloned into Bluescript plasmid KS-plus and were sequenced as described in the Materials and Methods section. The analysed fragment of $I_{2}$ has a length of $2004 \mathrm{bp}$. Its sequence has an in-frame stop codon at position 1518, followed by an untranslated stretch and a poly-A tail (not shown). This suggests that the

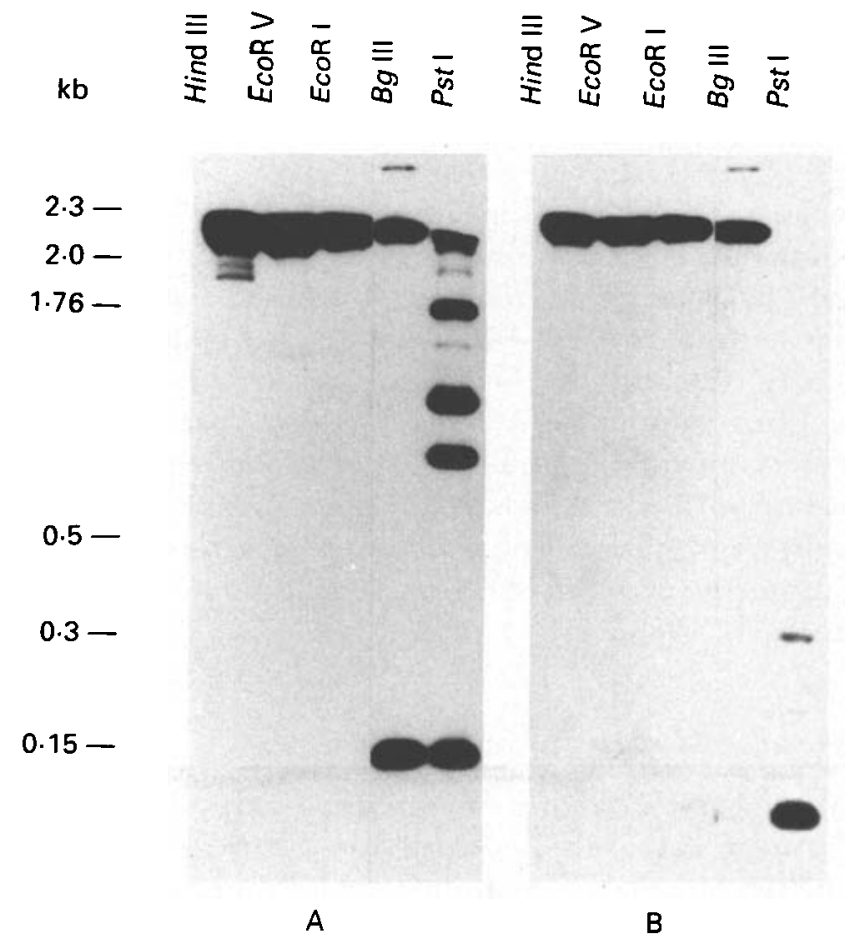

Fig. 4. Southern blot analysis of digested genomic Trypanosoma brucei brucei DNA. The DNA was hybridized with an $I_{2}$-specific probe $(A)$ and with an $I_{17}$ specific probe (B). Size markers are Hind III fragments of phage $\lambda$ DNA.

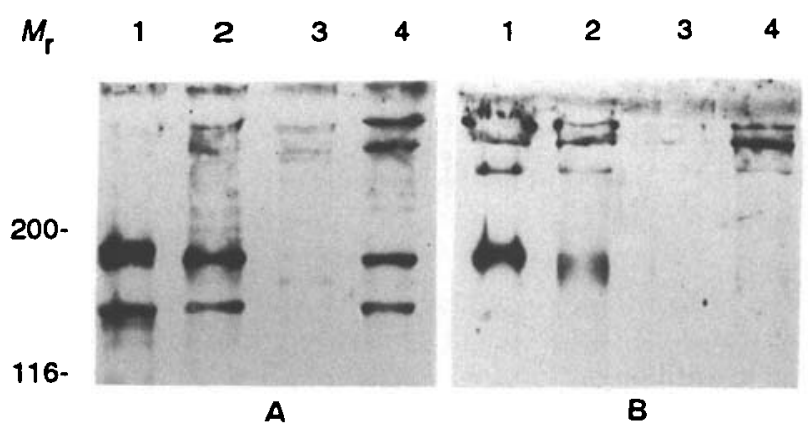

Fig. 5. Western blot analysis of different trypanosomal fractions. Lane 1 contains whole trypanosomal cell extracts, Lane 2 contains the cytoskeletal fraction of trypanosomes, Lane 3 corresponds to the supernatant of the cytoskeletal fraction and Lane 4 contains a flagellar fraction of cytoskeletons. In (A) the filter was probed with affinity-purified anti- $\mathrm{I}_{2} / \beta$-galactosidase fusion protein antibody and in (B) with affinity-purified anti$I_{1-} / \beta$-galactosidase fusion protein antibody. Molecular weight makers are given in $\mathrm{kDa}$.

cloned cDNA fragment of $I_{2}$ represents the $C$ terminus of the $I_{2}$ gene. A $1017 \mathrm{bp}$ stretch of the translated part (Fig. 3 A) consists of a highly conserved $135 \mathrm{bp}$ repeat. Only a single amino acid position of the repeat is not fully conserved and contains either alanine or threonine. The $3^{\prime}$ end of the coding sequence $(300 \mathrm{bp})$ is not repetitive. The analysed fragment of $I_{17}$ has a length of $1539 \mathrm{bp}$. The sequence has an in-frame stop codon at position 

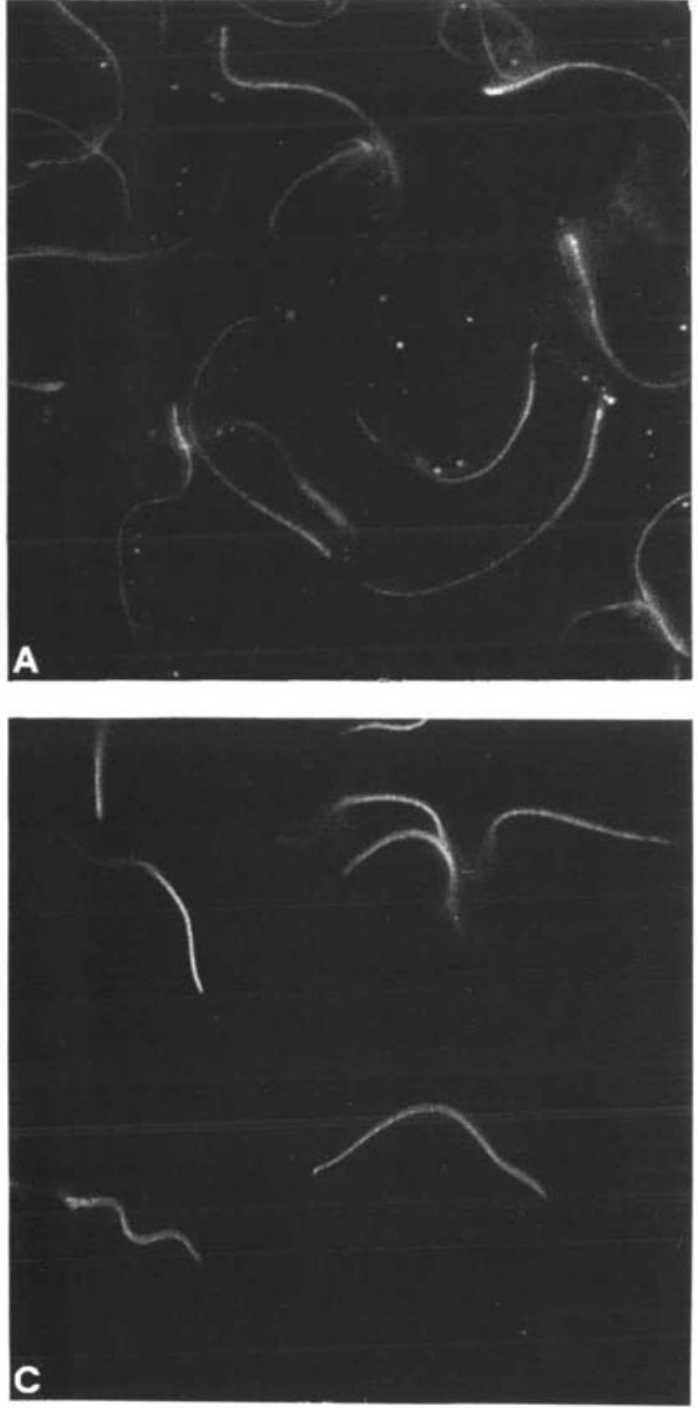
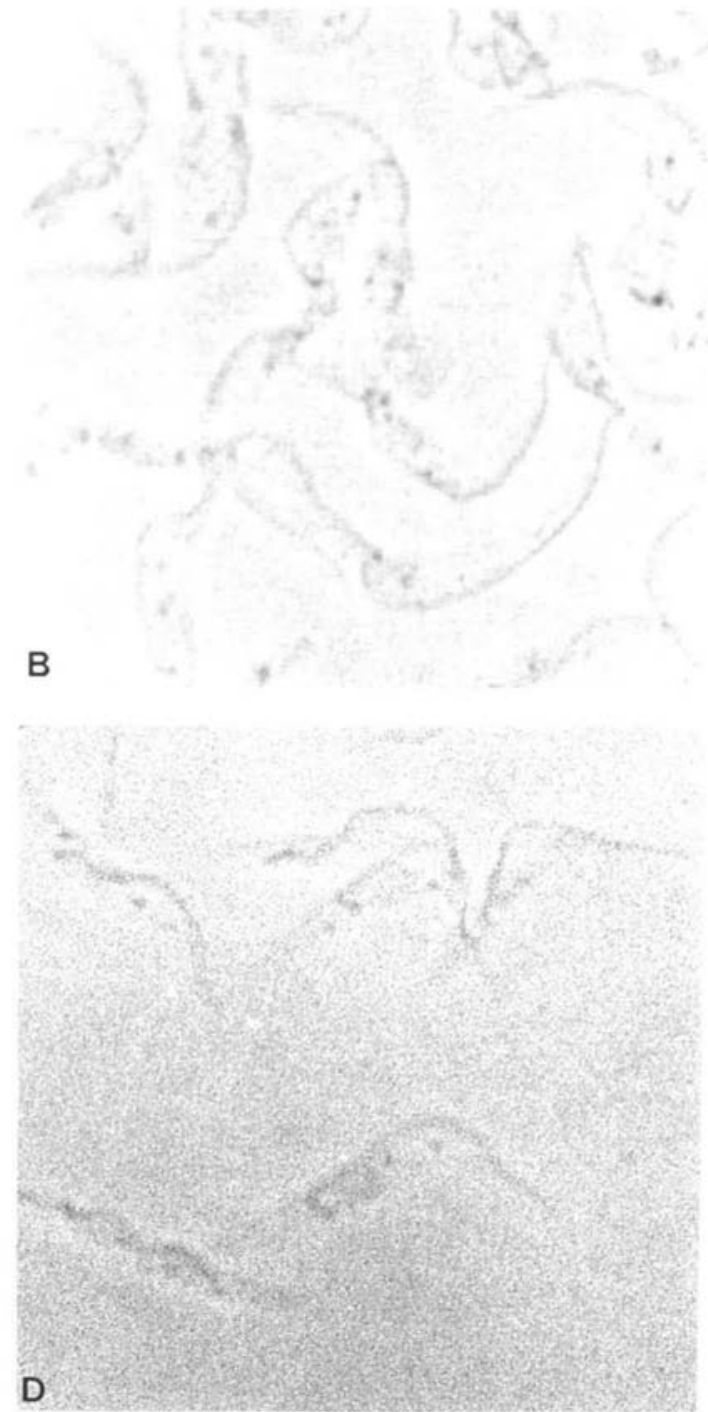

Fig. 6. Intracellular localization of $I_{2}$ and $I_{17}$ by immunofluorescence microscopy (A and C). The cytoskeletal preparation of procyclic Trypanosoma brucei bruce $i$ was probed with affinity-purified anti- $\mathrm{I}_{2} / \mathrm{I}_{17} / \beta$-galactosidase fusion protein antibody. The corresponding phase-contrast micrographs are shown in B and D.

1233, followed by about $300 \mathrm{bp}$ of untranslated region and a poly- $\mathrm{A}$ tail, which again indicates that the sequenced fragment represents the C-terminal part of the $I_{17}$ gene. The derived amino acid sequence of $\mathrm{I}_{17}$ is shown in Fig. $3 \mathrm{~B}$. Most of the $\mathrm{I}_{17}$ sequence $(1179 \mathrm{pb})$ consists of a highly conserved repeat of 87 bp with only 3 positions not fully conserved. The C-terminus of $\mathrm{I}_{17}$ is formed by a short stretch (14 amino acids) of non-repetitive sequence. Database searching with both the $I_{2}$ and $I_{17}$ amino acid sequences revealed no similarity with any known sequences.

\section{Genomic organization of the $I_{2}$ and $I_{17}$ gene}

The cDNA sequence of $I_{2}$ and $I_{17}$ showed that both genes are internally repetitive. The genomic organization of the genes of $I_{2}$ and $I_{17}$ was subsequently determined by restriction mapping. Genomic DNA of T.b. brucei was digested with restriction enzymes which either do or do not cut within the repeat sequence and was analysed by Southern blotting. Hybridization of genomic digests with an $I_{2}$-specific probe (Fig. $4 \mathrm{~A}$ ) revealed that $P$ st $\mathrm{I}$ and $B g l \mathrm{II}$, which both cut once within the $I_{2}$ repeat, generate a strongly hybridizing fragment, with the size of the repeat unit (135 bp). HindIII, Eco R V and Eco R I which do not cut within the repeat all generate large fragments $(>15 \mathrm{kDa})$. This observation indicates that $\mathrm{I}_{2}$ consists of the conserved $135 \mathrm{bp}$ repeat throughout most of its length. The additional fragments (1-2 kb) generated by Pst I may be indicative of occasional point mutations within the repeat.

Similarly, hybridization with the $I_{17}$-specific probe (Fig. 4B) gives a strong signal in the upper molecular weight range $(>15 \mathrm{~kb})$ for enzymes which do not cut in the repeat (HindIII, Eco R V, Eco R I and $B g l$ 

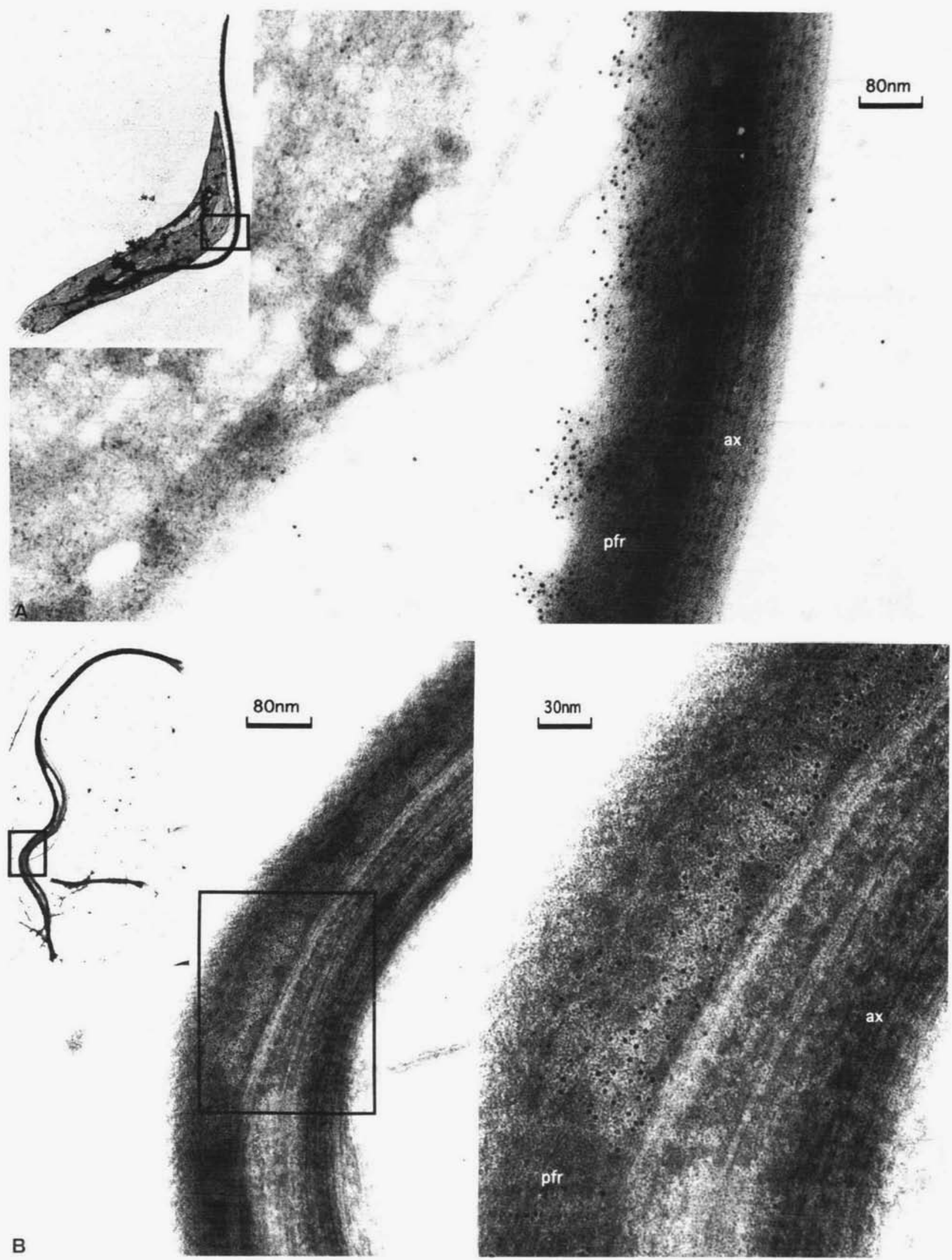

Fig. 7. Immunogold labelling of $I_{2}(A)$ and $I_{17}(B)$ with negatively stained whole-mount cytoskeleton preparation probed with the corresponding affinity-purified antibodies (see Materials and Methods section). (A) Gold particles are present mainly along the paraflagellar rod $(p f r)$ of the flagellum. (B) Gold particles cover the area between the paraflagellar rod and the axoneme $(a x)$ of the flagellum. 


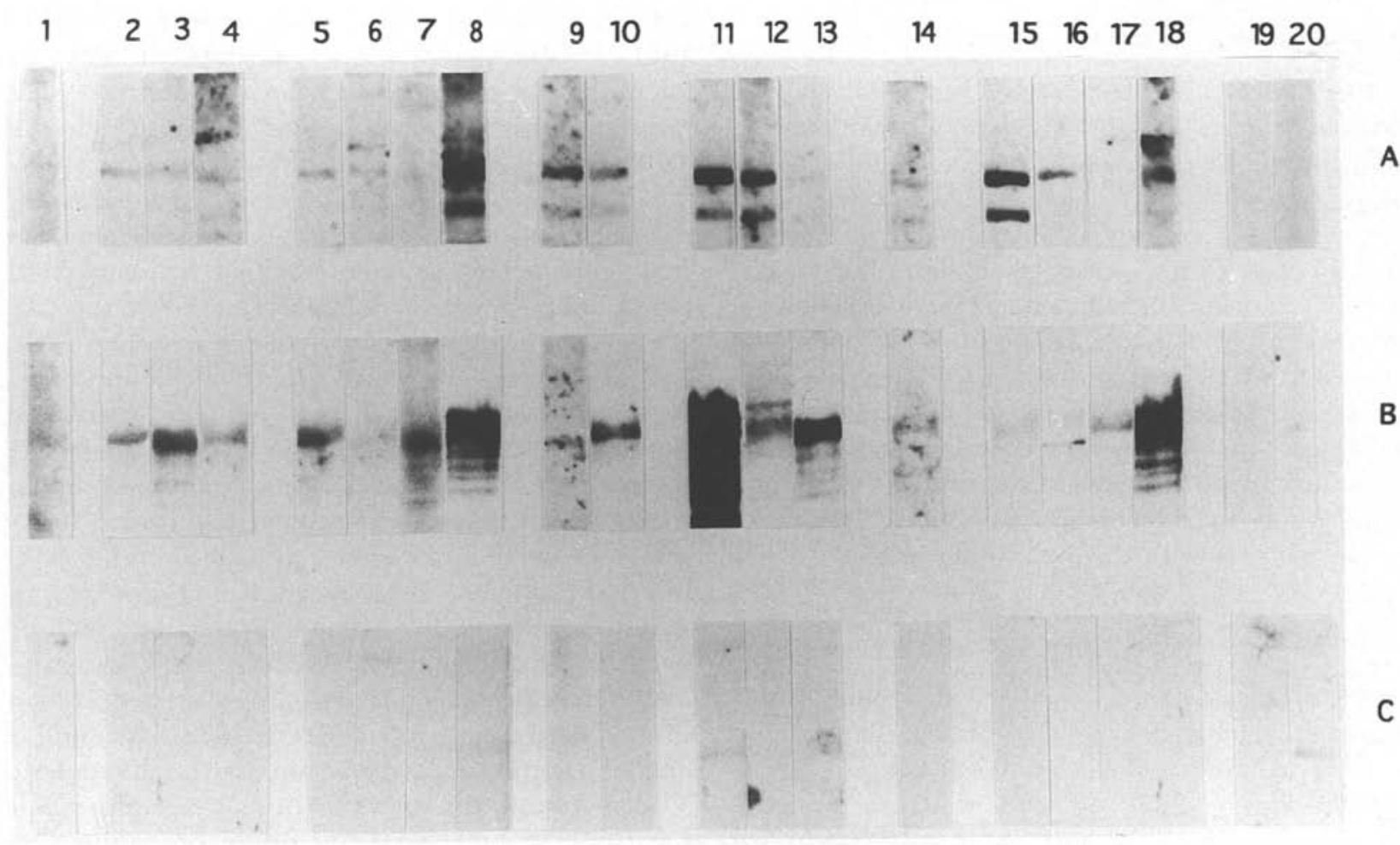

Fig. $\succ$. Western blot analysis demonstrating the diagnostic sensitivity of $I_{2}$ and $I_{17}$. Protein extracts trom $E$. colı lysogens of $\lambda \mathrm{I}_{2}(\mathrm{~A}), \lambda \mathrm{I}_{17}$ (B) and $\lambda \mathrm{gt11}$ (C) were blotted and cut into strips. Each strip was then incubated with a bovine serum. The sera originated from cyclical infections by Trypanosoma vivax (Lanes 2-4), T. congolense (Lanes 5-8), T. b. brucei (Lanes 1, 9, 10), or from mixed infections by T. b. brucei/T. vivax (Lanes 11-13) or T. b. brucei/T. congolense (Lane 14) or from experimental infections with $T$. congolense (Lanes 15-18). Strips 19 and 20 were incubated with two different uninfected sera.

II) whereas $P s t$ I, which cuts once within the repeat, generates a very strong band at about $90 \mathrm{bp}$. This correlates well with the size of the repeat defined by sequence analysis $(87 \mathrm{bp})$. The additional two faint bands correspond to dimers and trimers of the repeat unit. This is in good agreement with the available sequence data which show that the Pst I restriction site is missing in three of the 14 repeats sequenced. In contrast to $I_{2}$, the $I_{1}$, hybridization probe does not reveal additional bands, indicating that the whole $I_{17}$ gene has a repeated structure.

\section{$I_{2}$ and $I_{17}$ are both high molecular weight proteins}

The screening strategy used for gene isolation, as well as sequence and hybridization data predict that $I_{2}$ and $I_{17}$ both are high molecular weight proteins. In order to confirm this prediction at the protein level, the following Western blot analysis was performed. Whole cells, cytoskeletons and flagella of trypanosomes were prepared (see Materials and Methods section) and fractionated by SDS-PAGE. After transfer to nitrocellulose, they were probed with affinity-purified antibodies against $I_{2}$ and $I_{17} / \beta$ galactosidase fusion proteins. Both antibodies revealed several distinct bands in the high molecular weight $(>180 \mathrm{kDa})$ region. Both proteins are detected by immunostaining of whole cell extracts, in Triton-insoluble cytoskeletons and in saltextracted flagella (Fig. 5) indicating that both proteins are tightly associated to the flagellar cytoskeleton.

\section{Localization of $I_{2}$ and $I_{17}$}

Having established the tight association of $I_{2}$ and $I_{17}$ with the flagellar cytoskeleton, an immunofluorescent staining of cytoskeletons and whole cells with affinity-purified anti- $I_{2}$ and anti- $I_{17}$ antibodies was performed. The results of this staining are shown in Fig. 6. Both $I_{2}$ and $I_{17}$ antibodies induce a bright fluorescence along the flagellum. As both antibodies stain the flagellum with a very similar pattern, a more detailed localization was required. This was achieved by immunogold electron microscopy (Fig. 7). Antibody against $I_{2}$ reacts with the paraflagellar rod (Schlaeppi, Deflorin \& Seebeck, 1989) suggesting that $I_{2}$ is a component of this structure. In contrast, antibody against $I_{17}$ specifically stains the interface between the paraflagellar rod and the axoneme. While immunogold electron microscopy thus confirms the biochemical and immunofluorescence data indicating a close association of $\mathrm{I}_{2}$ and $\mathrm{I}_{17}$ with the flagellum, it further demonstrates that the detailed localization of the two proteins within the flagellum is quite distinct. 


\section{Immunodiagnostic potential of $I_{2}$ and $I_{17}$}

In order to evaluate the potential of $I_{2}$ and $I_{17}$ for diagnostic purposes, the respective $\beta$-galactosidase fusion proteins were used to analyse, by Western blotting, 18 sera from N'Dama and Zebu cattle with parasitologically confirmed infections with $T$. $b$. brucei, $T$. congolense, $T$. vivax, as single and as mixed infections. Also, two uninfected sera were included as controls. Fig. 8 demonstrates that $15 / 18$ infected sera reacted with $\mathrm{I}^{2}$ and $17 / 18$ with $I_{17}$ but none with the $\beta$-galactosidase control protein. All sera reacted with at least one of the two recombinant antigens. The serum which was taken 5 days after infection reacted with both recombinant antigens. No reactivity was seen with the 2 control sera.

\section{DISCUSSION}

In an earlier study we identified two trypanosomal antigens to which antibodies are produced early in an infection, MARP1 and GM-6 (Müller et al. 1992; Hemphill et al. 1992), as high molecular weight proteins both associated with the cytoskeleton. As both of them exhibited a high immunodiagnostic sensitivity $(90 \%)$, we wanted to know if African trypanosomes contain such additional cytoskeletal antigens. Therefore we have designed a screening protocol for the identification of these antigens. The present study described two antigens isolated by this strategy, $I_{2}$ and $I_{17}$. Both are high molecular weight proteins (MW $>180 \mathrm{kDa}$ ), both are highly internally repetitive and consist predominantly of conserved repeat units of 45 and 29 amino acids, respectively. Thus $I_{2}$ and $I_{17}$ share several important features with GM6 and MARP1, but all 4 proteins show neither amino acid sequence similarity nor immunological cross-reactivity (data not shown). $I_{2}$ and $I_{17}$ are both located in the flagellum, though at different locations within this structure. The data presented in Fig. 8 indicate that $I_{2}$ and $I_{17}$ might be of diagnostic interest in that they represent proteins which (i) are strongly immunogenic already in the early phase of infection, (ii) elicit an appreciable antibody response in all infected hosts, and (iii) are highly conserved between the African trypanosomatids ( $T$. brucei, $T$. congolense or $T$. vivax).

The finding that these trypanosome antigens are highly repetitive is in line with what we already have described for two other early antigens, MARP-1 and GM6 (Müller et al. 1992, 1993). These observations contribute to the emerging overall picture that the host antibody response both in the African trypanosomiases as well as in South American Chagas disease is strongly directed against parasite proteins which have the common denominators of being (i) very large and (ii) highly internally repetitive with a very high degree of sequence conservation between the individual repeat units (Ibanez et al. 1988; Hoft et al.
1989; Lafaille et al. 1989; Duncan, Gay \& Donelson, 1991; Pollevick et al. 1991; Burns et al. 1993). In addition, all these antigenic proteins are intracellular proteins, with the exception of SAPA, which is a GPI-anchored surface protein (Pollevick et al. 1991).

Several aspects of the molecular characteristics of these antigens are noteworthy. Already the mere fact that proteins consist of so many so well-conserved repeat units is peculiar. Highly repetitive proteins are not common in biology, and where they exist, e.g. spectrin in the erythrocyte, they exhibit a large extent of sequence variation between individual repeat units (Alcina et al. 1988). Conceptually, an internally repetitive organization of a protein might have evolved because the protein in question interacts with a repetitive substrate and is under evolutionary pressure to form many identical interactions with the substrate. This line of argument would be particularly cogent for MARP-1, which was originally identified as a microtubule-associated protein of trypanosomes (Schneider et al. 1988; Hemphill et al. 1992) and thus interacts with a lattice of regularly spaced tubulin dimers. However, although similar pressures should exist in other organisms, no comparable degree of repetitiveness is found elsewhere. Many microtubule-associated proteins from different organisms have been characterized and, where repetitive domains have been found, they consist of a small number of not very highly conserved repeat units (Lewis, Wang \& Cowan, 1988).

These findings argue that it is not the biological function of the various internal trypanosome antigens which exert the pressure to build up highly repetitive proteins and to maintain the observed near-perfect sequence conservation. So what does? Is it conceivable that the high molecular weight repetitive proteins have been generated by the trypanosome as devices for liberating, upon cell destruction by host defence mechanisms, large amounts of identical, immunologically active peptides which stimulate the immune system? Since many of the infecting trypanosomes are invariably destroyed at the site of an infection, this concept would guarantee a rapid and effective stimulation of the host's immune system, some parts of which might be beneficial for the parasite. The concomitant stimulation of antibodies against the peptides would be of no consequence to the trypansome because the target proteins are safely sheltered inside the cell. A similar situation is the strong stimulation of the host's immune response by the variant surface coat (VSG) which is the most prominent external antigen of the trypanosome (Cross, 1990). Here a different VSG-type population of parasites is already growing when the response against the former one is fully raised. Thus the parasite, after having stimulated a response against itself, can survive without any disadvantage. 
While we clearly need to learn much more about the possible roles of these repetitive proteins in the course of an infection, the available data demonstrate that they could play a most useful role, in a more practical sense, as diagnostic reagents.

We would like to thank Toni Wyler for his hospitality at the electron microscope and Yvonne Schlatter for her technical support. This work was supported by grant No. 31-30870.91 of the Swiss National Science Foundation and a grant of the Stanley Thomas Johnson Foundation.

\section{REFERENCES}

ALCINA, A., hargreaves, A. J., AVILA, J. \& FRESNo, M. (1988). The detection of a spectrin-like protein in Trypanosoma cruzi with a polyclonal antibody. Cell Biology International Reports 12, 979-85.

BARNES, D. A., MOTTRAM, J., SELKIRK, M. \& AGABIAN, N. (1989). Two variant surface glycoprotein genes distinguish between different substrains of Trypanosoma brucei gambiense. Molecular and Biochemical Parasitology 34, 135-46.

BRUN, R. \& SCHÖNENBERGER, M. (1979). Cultivation and in vitro cloning of procyclic culture forms of Trypanosoma brucei in semi-defined medium. Acta Tropica 36, 289-92.

BURNS, J. M., SHREFFLER, W. G., BENSON, D. R., GHALIB, H. W., BaDARO, R. \& REED, S. G. (1993). Molecular characterization of a kinesin-related antigen of Leishmania chagasi that detects specific antibodies in African and American visceral leishmaniasis. Proceedings of the National Academy of Sciences, USA 90, 775-9.

CRoss, G. A. M. (1990). Cellular and genetic aspects of antigenic variation in trypanosomes. Annual Reviews of Immunology 8, 83-110.

DE GEE, A. L., LEVINE, R. F. \& MANSFIELD, J. M. (1988). Genetics of resistance to the African trypanosomes. VI. Heredity of resistance and variable surface glycoprotein specific immune response. Fournal of Immunology 140, 283-8.

DOS SANTOS, C. N. D., KRIEGER, M. A., ALMEIDA, E., LAFAILLE, J. J., GOLDENBERG, S. \& GALLER, R. (1992). Trypanosoma cruzi flagellar repetitive antigen expression by recombinant Baculovirus - towards an improved diagnostic reagent for Chagas disease. Biotechnology 10, 1474-7.

DUNCAN, L. R., GAY, L. S. \& DONELSON, J. E. (1991). African trypanosomes express an immunogenic protein with a repeating epitope of 24 amino acids. Molecular and Biochemical Parasitology 48, 11-16.

HEMPHILl, A., AFFOLTER, M. \& SEEBECK, T. (1992). A novel microtubule-binding motif identified in a high molecular weight microtubule-associated protein from Trypanosoma brucei. Journal of Cell Biology 117, 95-103.

HEMPHILL, A., SEEBECK, T. \& LAWSON, D. (1991). The Trypanosoma brucei cytoskeleton: ultrastructure and localization of microtubule-associated and spectrinlike proteins using quick-freeze, deep-etch, immunogold electron microscopy. Fournal of Structural Biology 107, 222-20.

HOFT, D. F., KIM, K. S., OTSU, K., MOSER, D. R., YOST, W. J.,
BLUMIN, J. H., DONELSON, J. E. \& KIRCHHOFF, L. V. (1989). Trypanosoma cruzi expresses diverse repetitive protein antigens. Infection and Immunity 57, 1959-67. HYUNH, T. V., YOUNG, R. A. \& DAVIS, R. W. (1985). Construction and screening cDNA libraries $\lambda \mathrm{gt} 10$ and $\lambda$ gt11. In DNA Cloning 1 (ed. Glover, D. M.), pp. 49-78. Oxford: IRL Press.

IBANEZ, C. F., AFFRANCHINO, J. L., MACINA, R. A., REYES, M. B., LEguizamon, S., CAMARgo, M. E., ASLund, L., PETTERSON, U. \& FRASCH, A. C. C. (1988). Multiple Trypanosoma cruzi antigens containing tandemly repeated amino acid sequence motifs. Molecular and Biochemical Parasitology 30, 27-34.

LAFAILLE, J. J., LINSS, J., KRIEGER, M. A., SOUTO-PADRON, T., DE SOUZA, W. \& GOLDbERG, s. (1989). Structure and expression of two $T$. cruzi genes encoding antigenic proteins bearing repetitive epitopes. Molecular and Biochemical Parasitology 35, 127-36.

LAEMMLI, U. K. (1970). Cleavage of structural proteins during the assembly of the head of the bacteriophage T4. Nature, London 227, 680-5.

LAWSON, D. (1983). Epinemin: a new protein associated with vimentin filaments in non-neural cells. Fournal of Cell Biology 97, 1891-905.

LEWIS, S. A., WANG, D. \& COWAN, N. J. (1988).

Microtubule-associated protein MAP2 shares a microtubule-binding motif with tau protein. Science, 242, 936-9.

MÜLLER, N., HEMPHILl, A., IMBODEN, M., DUVALLET, G., DWINGER, R. H. \& SEEBECK, T. (1992). Identification and characterization of two repetitive non-variable antigens from African trypanosomes which are recognized early during infection. Parasitology 104, 111-20.

MÜLLER, N., IMBODEN, M., DETMER, E., MANSFIELD, J. M. \& SEEBECK, T. (1993). Cytoskeleton-associated antigens from African trypanosomes are recognized by selfreactive antibodies of uninfected mice. Parasitology 107, 411-17.

POLLEVICK, G. D., AFFRANCHINO, J. L., FRASCH, A. C. C. \& SANCHES, D. O. (1991). The complete sequence of a shed acute-phase antigen of Trypanosoma cruzi. Molecular and Biochemical Parasitology 47, 247-50.

RINDISBACHER, L., HEMPHILL, A. \& SEEBECK, T. (1993). A repetitive protein from Trypanosoma brucei which caps the microtubules at the posterior end of the cytoskeleton. Molecular and Biochemical Parasitology 58, 83-96.

RUIZ, A. M., ESTEVA, M., SUBIAS, E., MORENo, M., DECAMPANiNi, E., VELAZQUEZ, E. \& SEGUERA, E. L. (1990). Monoclonal antibodies against the flagellar fraction of epimastigotes of $T$. cruzi-immunoprotection against metacyclic trypomastigotes obtained by immunization of mice with affinity-purified antigen. Molecular and Biochemical Parasitology 39, 117-26.

SCHLAEPPI, K., DEFLORIN, J. \& SEEBECK, T. (1989). The major component of the paraflagellar rod of Trypanosoma brucei is a helical protein that is encoded by two identical, tandemly linked genes. Fournal of Cell Biology 109, 1695-709.

SCHNEIDER, A., HEMPHILL, A. \& SEEBECK, T. (1988). Large microtubule-associated protein of $T$. bruce $i$ has tandemly repeated, near-identical sequences. Science $241,459-62$. 
SEED, J. R. \& SECHELSKI, J. (1987). The role of antibody in African trypanosomiasis. Fournal of Parasitology $73,840-2$.

VOGEL, M., GOTTSTEIN, B., MÜLleR, N. \& SEEBECK, T. (1988). Production of recombinant antigen of Echinococcus multilocularis with high immunodiagnostic sensitivity and specificity. Molecular and Biochemical Parasitology 31, 117-26. WESSEL, D. \& FLüGGE, U. I. (1984). A method for the quantitative recovery of protein in dilute solution in the presence of detergents and lipids. Analytical Biochemistry 138, 141-3. 